\title{
Electrical Power Generation Using Footsteps
}

\author{
Iqbal Mahmud
}

Lecturer in Mechanical Engineering, Department of Textile Engineering, Bangladesh University of Business and Technology (BUBT), Bangladesh

Doi: 10.19044/esj.2018.v14n21p318 URL:http://dx.doi.org/10.19044/esj.2018.v14n21p318

\begin{abstract}
Electricity is the most general forms of energy used across the world. This paper focuses on designing a setup that leads to the generation of electrical energy which is going to waste when humans are walking. Footsteps are an untapped natural resources. This generated energy is, however, costeffective and nonhazardous for human. Electrical energy can be produced by converting mechanical energy using footsteps. Generating the electric power through the fabrication of footstep arrangement by a prototype comprises of a pipe, nozzle, unidirectional valve, water reservoir, turbine, and DC motor. Whenever pressure is exerted on the reservoir, water flows through the nozzle into the turbine and generates electrical energy. This energy is stored in the battery. This project will reduce the global warming and load shedding in a much cleaner cost-effective way. Since this project is related directly to the human movement, the weight of the setup is a crucial factor.
\end{abstract}

Keywords: Electric power generator, Piezoelectric device, Footstep electronics tool, hydraulic pressure, sustainable energy

\section{Introduction}

The process of producing electrical power from different types of energy sources is called electricity generation. This type of energy is an essential part of nature. We generate electricity (secondary energy source) by converting primary sources of energy like atomic, gasoline, coal, and other natural sources. Fossil fuels pollute the environment. Atomic power plant requires careful handling of both raw as well as waste material. From the birth of earth, man has needed and used energy at an increasing rate prior to his existence. The world has already used large amount of energy resources for power production. The extensive usages of available resources in recent years created a demand for the future generation (Magdum, Chikhale, Rajole, \& Jedhe, 2017). After realising the availability issues of the non-renewable sources, the renewable sources of energy like wind, water, and sun are being consistently and increasingly used by people to generate power. Therefore, 
our focus now is on the renewable energy, which is essential and nonpolluting. Have we ever thought that we could generate electricity with our footsteps? Walking is a widespread practice every day. A person transfers energy through impact or vibration to the road surface. This energy can be converted to electrical energy by subsequent conversion of mechanical energy. Whenever we move on our feet, our kinetic energy is wasted as heat energy. In this project, we have originated electricity through the humanpowered mechanical energy.

\section{Literature Survey}

The burning of coal, wood, diesel (generators) and so forth are used for traditional power generation method, which is continuously depleting our natural resources such as fossil fuels (Sekhar, kishore, \& Raju, 2014). The demand for power rises with the increase in population. Besides, the traditional methods cause pollution and encourage deforestation (cutting of trees). Therefore, this results to consequences such as global warming, power shortage just like what we are facing in Bangladesh.

Global warming indicates an average rise of the temperature in the atmosphere near the Earth's surface. The global surface temperature increased $0.74 \pm 0.18^{\circ} \mathrm{C}\left(1.33 \pm 0.32^{\circ} \mathrm{F}\right)$ during the 100 years ending in 2005 (Global Warming-Climate 365). Since the mid-twentieth century, the temperature rises with the intensity of anthropogenic greenhouse gas. Solar variation, volcanoes, and cooling effect contributes to the entropy rise from pre-industrial age to nowadays,

IPCC indicate that average global surface temperature will likely rise further from 1.1 to $6.4^{\circ} \mathrm{C}\left(2.0\right.$ to $11.5^{\circ} \mathrm{F}$ ) (Portal: weather/selected Article/6, 19) during the 21 st century. Most studies up to 2100 show that entropy and sea level continuously rise. The rate of reaching equilibrium is slow due to the high heat capacity of the sea.

Scientists have stated with 66-90\% confidence that the effects of human-caused aerosols and volcanic activity have a significant effect on global warmings, and that greenhouse gases accelerate the warming. The steady decline of the depletion of ozone in the Earth's stratosphere is regarded as global warming.

\section{Problem Definition}

Some developing countries, in almost all cities and villagers, faces several hours of daily load shedding due to uneven demand for electricity with the electric power generation rate. Many developed countries use gasoline electric generator and IPS (Instant power supply) at their homes during the power-cut. Industry and IT hubs also use standby generator due to power crisis. This system ultimately intensifies the crisis of power. 


\section{Existing System}

There are five ways to transform footsteps into electrical energy:

\section{NTT's Electricity Generating Shoe}

Japanese telecommunications giant, NTT, has developed shoes that generates electricity from the kinetic energy generated walking. The shoe that looks like an orthopaedic sandal is sturdy enough to generate $1.2 \mathrm{~W}$, which is sufficient to juice up an iPod. This occurs whenever weight is placed on water cushioned soles and the water sloshes on the mini turbines to generate electric power. The small generator provided in the each of the pair of the shoes can produce an adequate amount of electricity, which can be used to charge digital musical device for as long as possible.

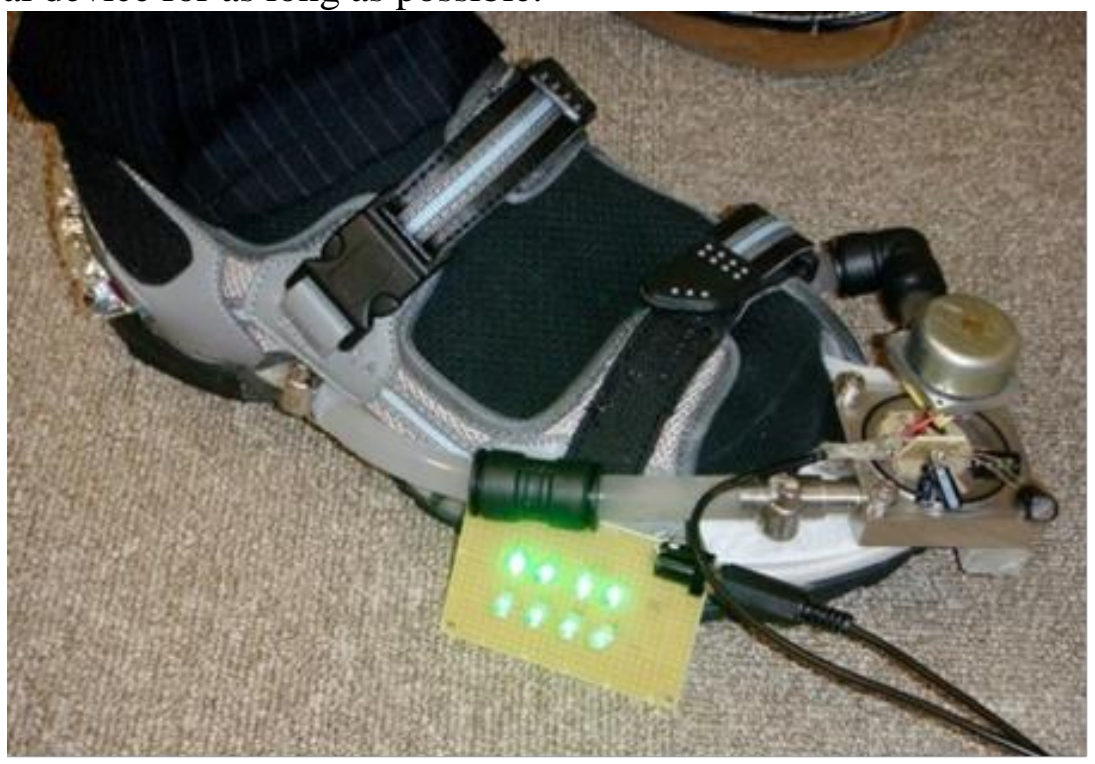

Figure 2.1. NTT's electricity generating shoe (Engadget, 2008)

\section{"Nano Power" Shoes}

We lost around 20W in each step forward in the form of heat. A research team of Wisconsin Madison University has made fantastic substrate footwear. The shoe is made up of a viscous liquid with tiny metal microdroplets. The footsteps of the wearer made the mini droplets to flow in the substrate under pressure to produce electricity by a process called reverse electro-wetting. This technique is eco-friendly with low cost. 


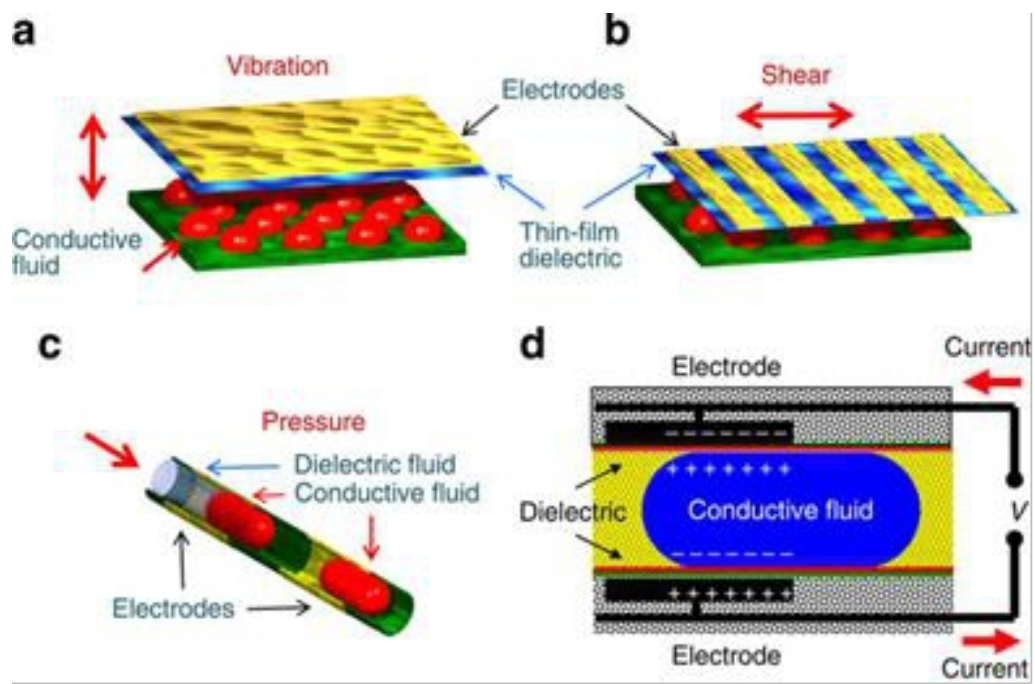

Figure 2.2. These include (a) droplets between oscillating plates, (b) droplets between sliding plates, and (c) droplets in a microchannel. (d) Shows in greater details the schematics of reverse-electrowetting-based energy generation process in a microchannel geometry (Krupenkin \& Taylor, 2011).

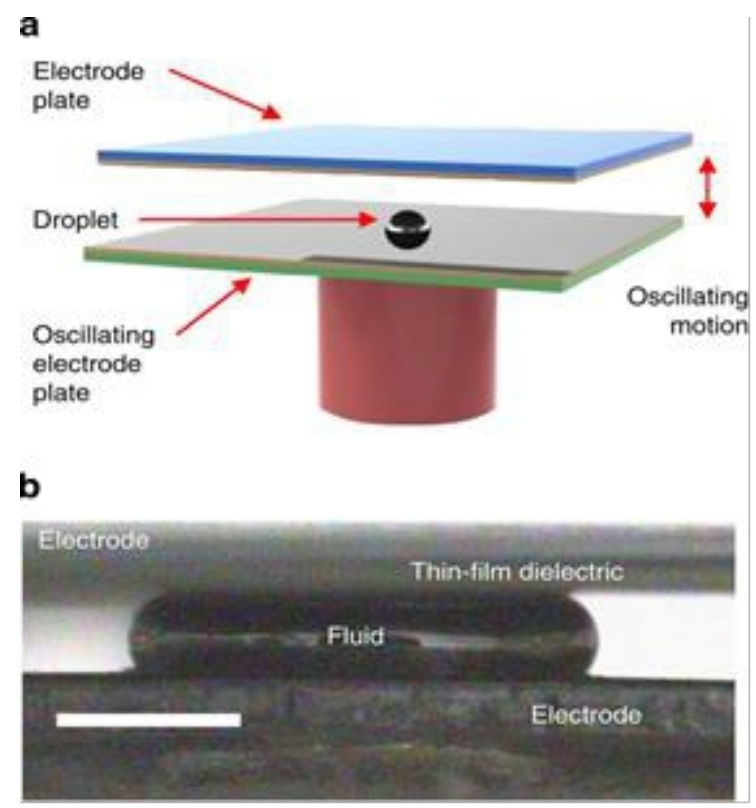

Figure 2.3. (a) Schematics of the device and (b) a frame from a high-speed video showing a side view of a droplet squeezed between two electrodes. Scale bar represents $0.5 \mathrm{~mm}$ (Krupenkin \& Taylor, 2011).

\section{Motion on Dance Floor Generates Green Electricity}

The Dutch architectural firm, Doll, teamed up with environmental organisation, Enviu, to create the green energy which results to a Sustainable Dance Club in Rotterdam, Netherlands. Whenever clubbers hit the dance 
floor, kinetic energy is produced. This energy is collected by the micro-sensor module set under the dance floor and is converted to green electricity. This sustainable energy is used to power the lighting systems of the club.

\section{Generate Power using Footsteps by a Spring Mechanism}

In this process, the main components are a plate, spring, and connecting rods. Whenever pressure is applied to the plate by the spring, the connecting rods pushed downwards. Subsequently, a DC motor fitted to the rods rotates causing the generation of electrical energy.

\section{Streetlights Powered by Sidewalks}

Recently, the city officials of Toulouse, France, have installed powergenerating tiles made of piezoelectric power technology on the sidewalks in the city centre. The embedded microsensors in eight tiles could generate 5060 watts of power by the pressure of the footsteps by the pedestrians. This green energy is quite enough to lighten up a nearby street lamp.

\section{Proposed System}

The design is an innovative and iterative process. It is also a decisionmaking process. This design is subject to problem-solving constraints. In the design, the footwear consists of water cushioned soles. Thus, whenever we put pressure by the weight of the body on it, the water flows to the mini turbines and produce electric power. Each of the pairs of the shoes possesses its small generator to produce an adequate amount of electricity. Various types of devices were considered for generating electricity. Preferably, a dynamo would have been best suited for our intentions. However, due to their relative unavailability and high costs, various alternatives had to be considered. Running most electric motors in their reverse direction would serve our purposes equally well. 


\section{Block Diagram}
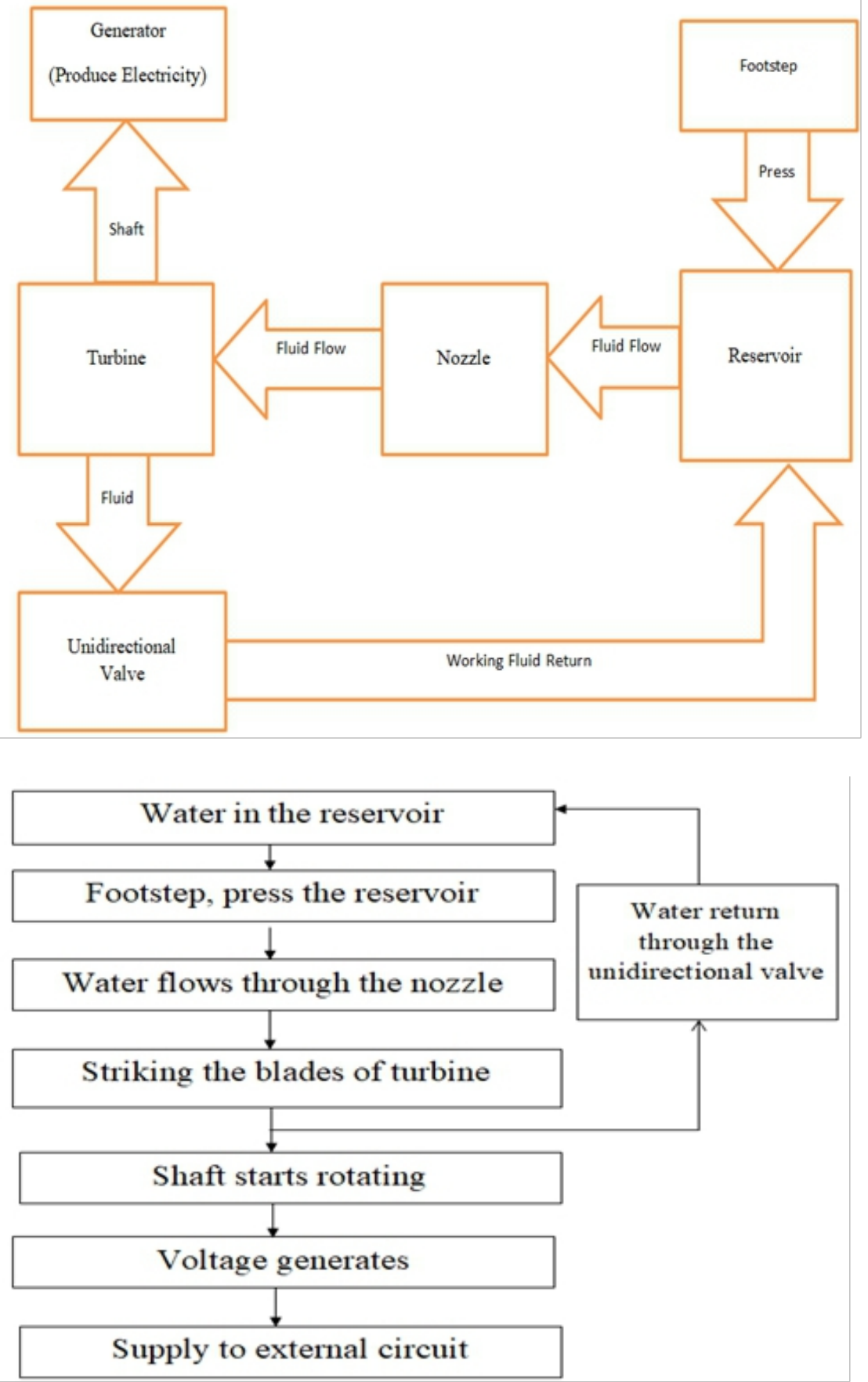


\section{Experimental Setup}

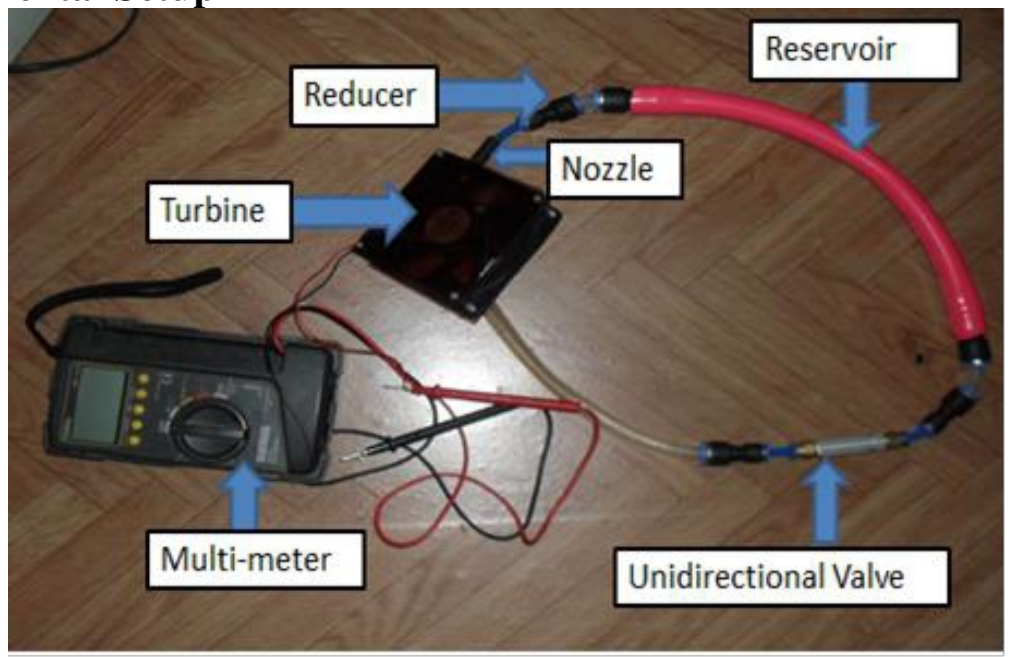

Figure 4.1. Experimental setup

In this project, a nozzle was used to strike the fan (turbine). Also, a more significant diameter pipe was used as a reservoir. The water goes from the reservoir to the nozzle through a reducer ( $10 \mathrm{~mm}$ to $6 \mathrm{~mm}$ ). Water return to the reservoir through the unidirectional valve. Unidirectional valve is set up between reducer $(10 \mathrm{~mm}$ to $6 \mathrm{~mm})$ and expander $(6 \mathrm{~mm}$ to10 $\mathrm{mm})$. The expander is then connected to the reservoir.

\section{Description of Parts Nozzle}

A nozzle (often a pipe or tube of the varying cross-sectional area) is a device used to increase or decrease velocity and the direction of the fluid flow. It mainly converts pressure energy to the kinetic energy of the flowing medium. Nozzle could be convergent (gradually decreasing cross-section), divergent (gradually increasing cross-section), or convergent-divergent. Depending on Mach number, the stream accelerates or deaccelerates in the nozzle. For subsonic flow (Mach no<1), an increase in the area is associated with decrease in velocity and vice versa. In case of supersonic flow (Mach no>1), an increase in the area is associated with increase in velocity and vice versa. At sonic point $($ Mach no=1), flow will be choked in the minimum area (throat) or maximum area (bulge).

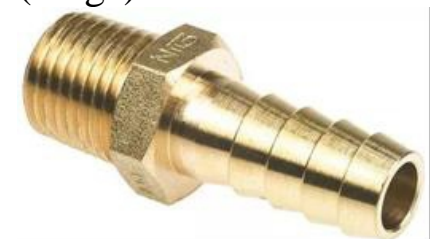

Figure 5.1. Nozzle (Hakimi Hydraulics \& fittikings) 


\section{Reducer}

A reducer reduces the inner diameter of the pipe from a larger to a smaller bore in a pipeline. A reducer can be used either as a nozzle or as a diffuser depending on the Mach number of the flow (Pipe fitting-Ss cross Exporter).

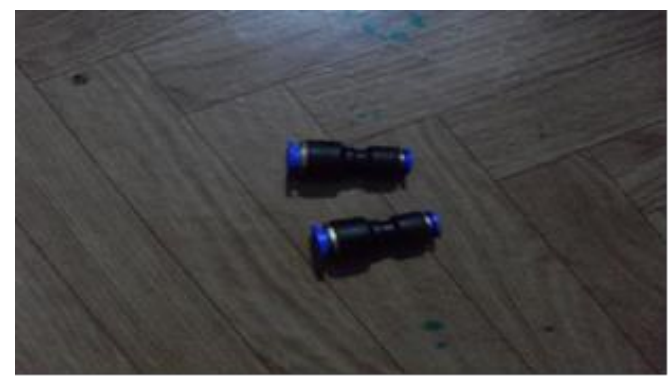

Figure 5.2. Reducer

\section{Unidirectional Valve}

Check valve, non-return valve or unidirectional valves are used to prevent reverse flow. These valves are two-port valves, meaning they have two openings in the body, one for fluid to enter and the other for fluid to leave (Check Valve-Wikipedia). These valves are working on cracking pressure. The minimum upstream pressure which is required to operate the valve is called cracking pressure.

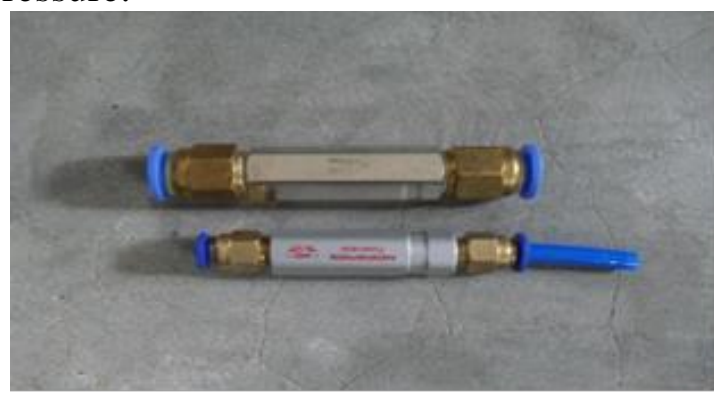

Figure 5.3. Unidirectional Valve

\section{Pipe}

A closed conduit used to convey fluid is called pipe. There are different types of flow in the pipe based on the velocity of the fluid. The material of the pipe also has a significant impact on the flow.

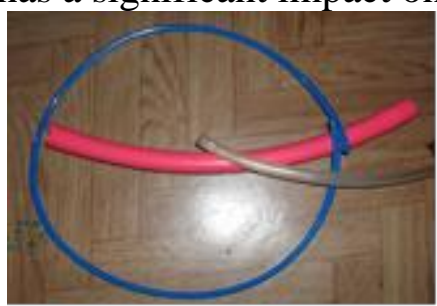

Figure 5.4. Different types of Pipe 


\section{Turbine}

A turbine is a rotary mechanical device that extracts energy from a fluid flow and converts it into useful work. The work produced by a turbine can be used for generating electrical power when combined with a generator (Liddell \& Scott, 1843). A 2-wire PC fan is used as a turbine which has a male-female Molex 4-pin connector from where their power supply is drawn.

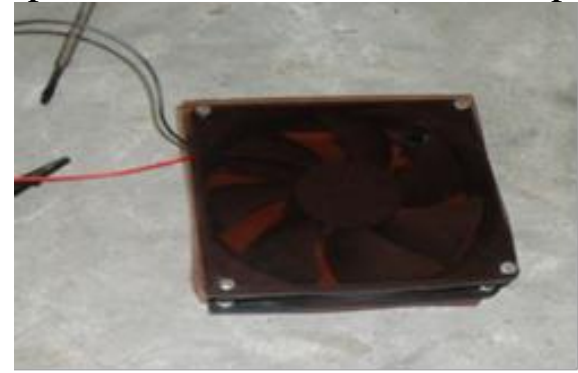

Figure 5.5. Turbine

\section{Multi-meter}

A multimeter is a test tool used to measure mainly voltage (volts), current (amps), and resistance (ohms). A moving pointer in analogue multimeters is used to display readings. Digital multimeter has a numeric display.

\section{Generator}

According to Faraday's laws of electromagnetic induction, whenever a conductor is placed in a varying magnetic field (or a conductor is moved in a magnetic field), an emf (electromotive force) is induced in the conductor (Basic Construction and Working of a DC Generator). The stator act as the field magnet and the rotor is attached to the turbine. Fleming's right-hand rule is used to find the direction of the induced current.

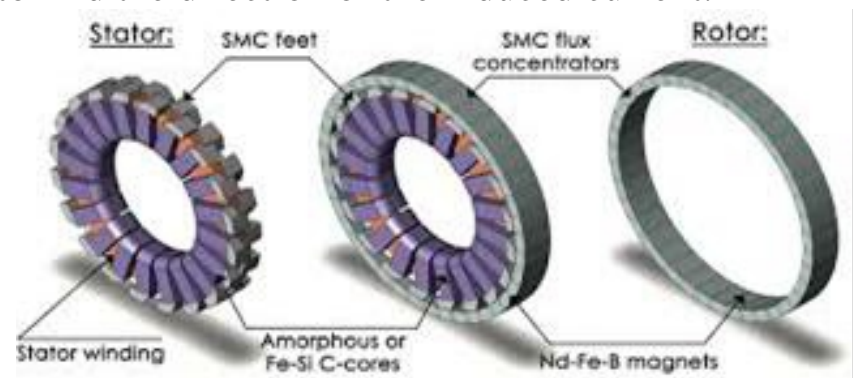

Figure 5.7. Stator and Rotor (Dubois, Dehlinger, \& Trovao, 2017)

\section{Result and Discussion}

Three experimental setups are used to collect data. The output voltage and current were taken directly from the multimeter. The output power and efficiency measurement were performed three times for different dimension 
of the turbine casing. Therefore, we can measure the output power and efficiency by the following equation:

Output power $=$ output voltage $\times$ current induced

$$
\text { Efficiency }=\frac{\text { Output power }}{\text { Maximum capacity }} \times 100 \%
$$

Table No.1. Data from three experimental setup

\begin{tabular}{|c|c|c|c|c|c|}
\hline $\begin{array}{c}\text { Turbine } \\
\text { Casing } \\
\text { (inch } \times \text { inch) }\end{array}$ & $\begin{array}{c}\text { Maximum } \\
\text { Capacity } \\
(\mathbf{W})\end{array}$ & $\begin{array}{c}\text { Output } \\
\text { Voltage (V) }\end{array}$ & $\begin{array}{c}\text { Current } \\
\text { Induced (A) }\end{array}$ & $\begin{array}{c}\text { Output } \\
\text { Power (W) }\end{array}$ & $\begin{array}{c}\text { Efficiency } \\
(\boldsymbol{\%})\end{array}$ \\
\hline$(3 \times 3)$ & 1.44 & 0.623 & 0.3 & 0.1869 & 13 \\
\hline$(5 \times 5)$ & 2.16 & 0.687 & 0.3 & 0.2061 & 9.54 \\
\hline$(5 \times 5)$ & 3.60 & 0.728 & 0.3 & 0.2184 & 6 \\
\hline
\end{tabular}

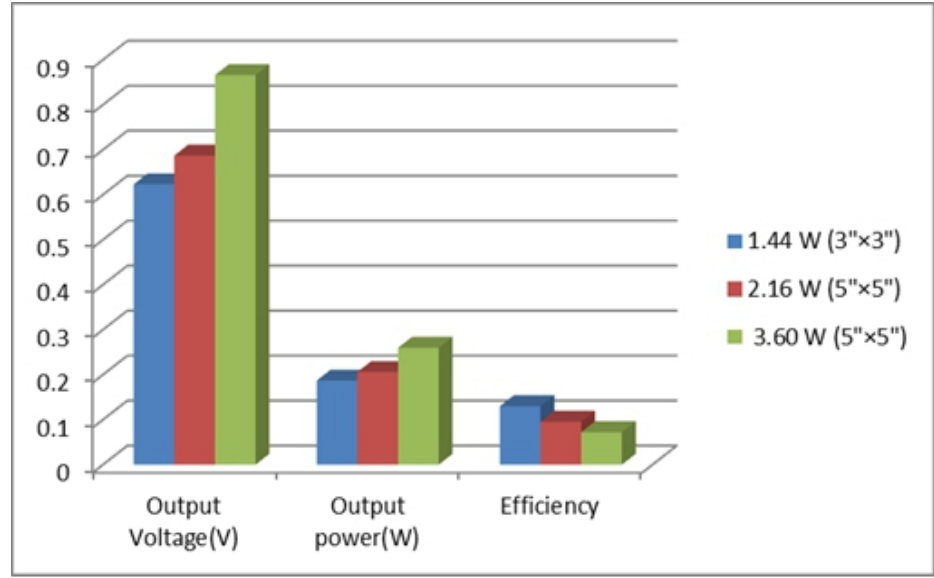

Graph 1. Comparison in three experimental setup

\section{Conclusion}

The waste energy of human during walking is used in this system. Footstep is an uninterrupted and renewable source of energy. The system repeatedly operates in a short duration of time and is not possible for the turbine to maintain a constant speed. As a result, voltage variation occurred which is controlled by a voltage regulator. The total system of the power generation using footsteps depend mainly on the angle of attack of the flowing medium. High voltage dynamo should be used to produce more electricity. Though many systems are available for power generation from footsteps, the proposed system is very economical and affordable. As Bangladesh is a developing country with a large population, we face difficulty day by day due to power shortage. Many people in our country cannot enjoy the facility used for generating electricity. Though power produced in this process is minimal, as a whole country, this will be a considerable source of electrical energy. This project also reduces global warming. 


\section{References:}

1. Engadget $(2008,10$ 20). Retrieved 6 5, 2018, from www.engadget.com: //www.engadget.com/2008/10/20/ntts-energygenerating-shoes-spotted-without-any-sign-of-stylis/

2. Basic Construction and Working of a DC Generator. (n.d.). Retrieved April 26, 2018, from Electrical Easy.Com: //www.electricaleasy.com/2012/12/basic-construction-and-workingof-dc.html

3. Check Valve-wikipedia. (n.d.). Retrieved April 2018, 04, from //en.wikipedia.org/wiki/one-way_valve

4. Dubois, M., Dehlinger, N., \& Trovao, J. (2017). Optimization of complex 3-D PM machines in Excel-Visual Basic-MagNet3D environment: case of the Clawpole Transverse Flux Machine. Engage conference 2017, (p. 2). Miami, FL, USA.

5. Global Warming-Climate 365. (n.d.). Retrieved April 04, 2018, from Google Sites: Sites.google.com/a/climate365.com/www/globalwarming

6. Hakimi Hydraulics \& fittikings. (n.d.). Retrieved from www.hakimihydraulics.com: //www.hakimihydraulics.com/brasshose-nozzle-3601555.html

7. Krupenkin, T. \& Taylor, J. A. (2011). Reverse electrowetting as a new approach to high-power energy harvesting. NATURE COMMUNICATIONS, 2.

8. Krupenkin, T. \& Taylor, J. A. (2011). Reverse electrowetting as a new approach to high-power energy harvesting. NATURE COMMUNICATIONS, 6 .

9. Liddell, H.G. \& Scott, R. (1843). A Greek-English Lexiconat the perseus project. Oxford: Oxford University Press.

10. Magdum, P. R.,Chikhale, S. J., Rajole, A. S., \& Jedhe, S. S. (2017). Generation of Electricity by Using Footsteps as a Source of Energy. IOSR Journal of Mechanical and Civil Engineering (IOSR-JMCE), 50.

11. Pipe fitting-Ss cross Exporter. (n.d.). Retrieved April 2018, 04, from //www.ratnaexports.com/pipe-fittings.html

12. Portal:weather/selected Article/6. (19, April 2017). Retrieved from Wikipedia: //en.wikipedia.org/wiki/Portal:Weather/Selected_article/6

13. Sekhar, A., kishore, B., \& Raju, T. (2014). Electromagnetic Foot Step Power Generation. International Journal of Scientific and Research Publications, 3027. 